\title{
Retaining ALK Rearrangement in Cultured Circulating Tumor Cells Derived from Lung Cancer Patients
}

\author{
Eunjoo Hwang ${ }^{1}$, Dong-Hyoung Lee ${ }^{1}$, Ji-hyun Uh ${ }^{1}$, Duyeol Han ${ }^{1}$, Myoung Shin Kim ${ }^{1}$, Sung Ho Choi ${ }^{1}$, \\ JooKyung Park ${ }^{2}$, Byung Hee Jeon ${ }^{1}$, Jinseon Lee ${ }^{1}$, Se-Hoon Lee ${ }^{2}$ \\ ${ }^{1}$ Cytogen Inc., Seoul, Korea \\ ${ }^{2}$ Department of Internal Medicine, Seoul National University Hospital, Seoul National University College of Medicine, Seoul, Korea
}

\section{Email address:}

jslee@cytogenlab.com (Jinseon L.), sehoon.lee119@gmail.com (Se-Hoon L.)

\section{To cite this article:}

Eunjoo Hwang, Dong-Hyoung Lee, Ji-hyun Uh, Duyeol Han, Myoung Shin Kim, Sung Ho Choi, JooKyung Park, Byung HeeJeon, Jinseon Lee, Se-Hoon Lee. Retaining ALK Rearrangement in Cultured Circulating Tumor Cells Derived from Lung Cancer Patients. Cancer Research Journal. Vol. 3, No. 1, 2015, pp. 11-16. doi: 10.11648/j.crj.20150301.13

\begin{abstract}
Circulating tumor cells (CTCs) are rare cells that have shed into the bloodstream from primary tumor, and potentiallyprovidea tool for the better understanding of tumor metastasis and noninvasive monitoring of the disease progression. However their isolation and characterization has been a major technological challenge due to their rareness. Here, we suggest the CTC culture as an effective method to obtain CTCs sufficient in numberfor molecular analysis of original tumor characteristics. We isolated and successfully cultured the CTCs from four lung cancer patients, and then analyzed those cells for ALK (anaplastic lymphoma kinase) fusion using real-time PCR method, and confirmed that the cultured CTCs have retained thefusion the same as those found in primary tumors. These results suggest that the isolation and culture of CTCs can be a substitutive method for tumor tissue biopsy, and may provide practically useful clinical applications, such as personalized cancer therapy based on their genomic information through serial blood samplings from the cancer patients.
\end{abstract}

Keywords: Lung Cancer, Circulating Tumor Cells, ALK Rearrangement, Real Time PCR

\section{Introduction}

Circulating tumor cells (CTCs) are present in the blood of cancer patients at extremely low concentrations. It has been proposed that CTCs may be a prognostic marker for cancer progression and survival in several types of cancer $[1,2]$ and a potential source of the metastatic tumor cells $[3,4]$. Viable CTCs isolated from cancer patients can be a useful tool for identifying molecular targets and developing new cancer treatments, especially for the patients at the stage of disease progression [5]. However, the isolation and characterization of CTCs is technically challenging due to their rareness and heterogeneity [6].

Lung adenocarcinoma is the most common subtype of lung cancer today. Recently, the treatment paradigm for advanced non-small cell lung cancer (NSCLC) has been transformed from conventional chemotherapy to targeted therapy based on molecular aberrations in primary tumor [7]. Now, it has been regarded as a standard procedure to test lung tumor for the presence of $E G F R$ mutation and $A L K$ rearrangement upon diagnosis in order to select patients for the targeted therapy using $E G F R$ tyrosine kinase inhibitor (TKI)and $A L K$ inhibitor. However, detection of such molecular abnormalitiesin tumor cells during the course of therapy is hampered due to the difficulty in obtaining tumor cells from repeated tissue biopsies [8]. For this reason, we explore whether CTCs can be expanded through in vitro culture, and the cultured CTCs retain the same molecular characteristic as those of primary tumor. Here, we present evidence that CTC culture could generate sufficient amount of CTCs and their molecular analysisproves to retain the molecular abnormality in the primary tumor, which implies that CTC culture can be a substitutive method for tumor tissue biopsy.

\section{Materials and Methods}

\subsection{Blood Collection}

Blood samples $(5-10 \mathrm{ml})$ were collected from advanced NSCLC cancer patients by venipuncture at Seoul National University Hospital, and transferred to Cytogen laboratory in less than 4 hours. Written informed consent was obtained from all patients, with prior approval from the IRB of Seoul 
National University College of Medicine.

\subsection{Primary Culture of CTCs}

Whole blood was processed to enrich the CTCs, described previously [9].Enriched CTCs were collected and washed with RPMI-1640 medium. Cells were cultured in $60 \mathrm{~mm}$ plates containing growth medium (RPMI-1640 mediumwith $10 \%$ FBS, $2 \%$ Streptomycin, Penicillin, AmphotericinB) at $37^{\circ} \mathrm{C}, 5 \% \mathrm{CO}_{2}$ for $16-18$ days.
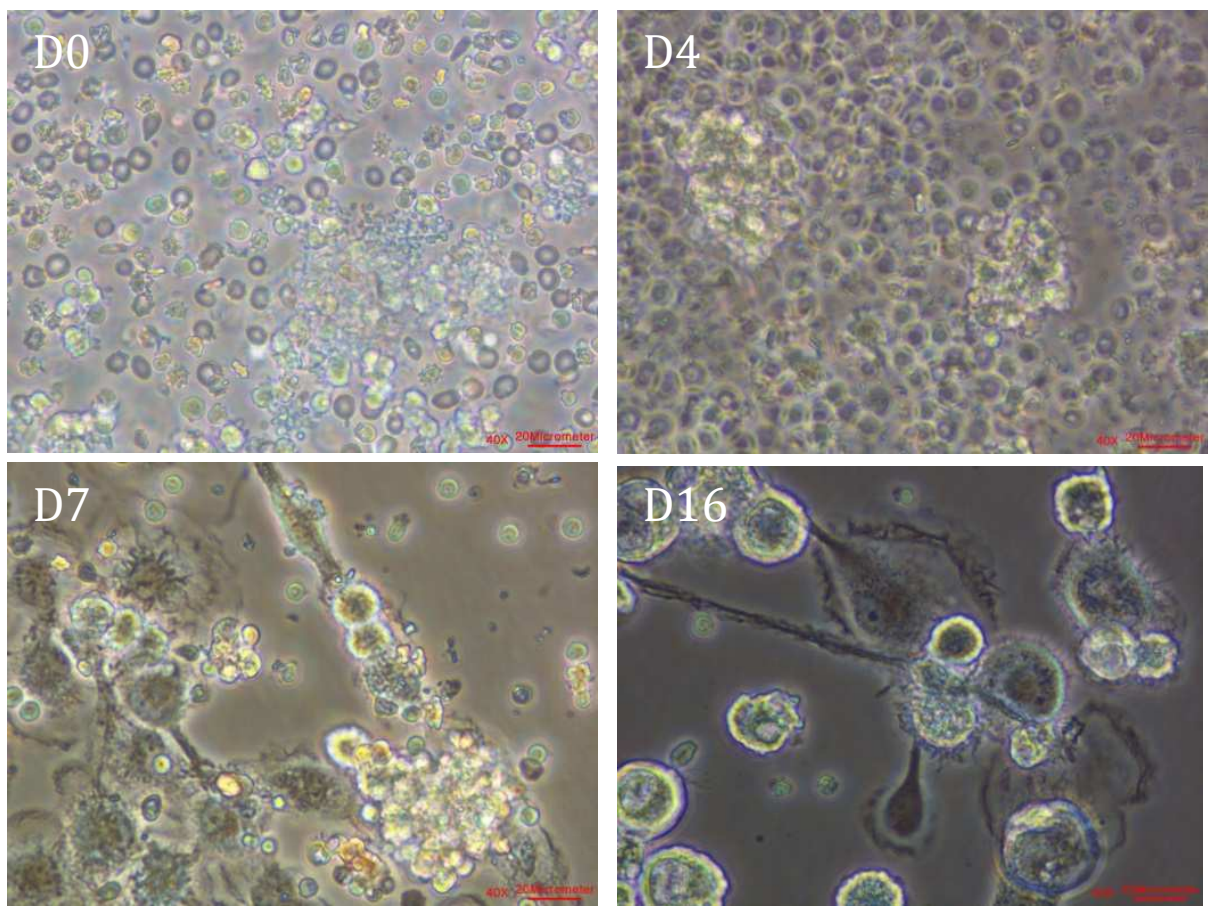

Figure1. Representative images of cultured CTCs at day 0, 4, 7, and 16 (X400).

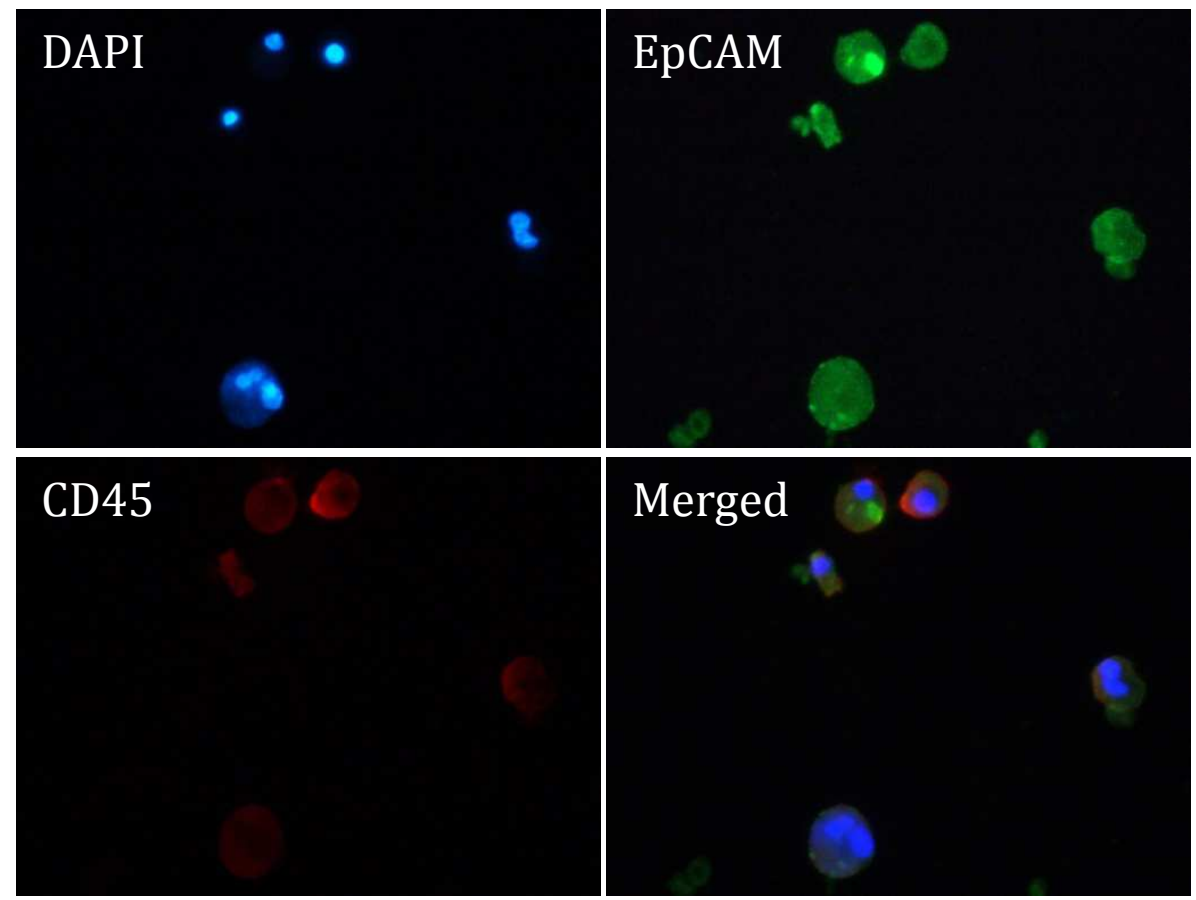

Figure 2. Immunofluorescent staining for EpCAM (green), CD45 (red), and nuclei (blue) (X400).

\subsection{Immunofluorescence Analysis}

Cells were fixed with $4 \%$ formaldehyde for 5 minutes at room temperature and permeabilized for 10 minutes with $0.2 \%$ Triton X-100 in PBS. Cells were quenched for 1 hour with $0.3 \%$ hydrogen peroxide, blocked with $1 \%$ BSA in PBS for 1 hour, and incubated with primary antibodies followed by 
secondary antibody incubation. Primary antibodies were mouse anti-EpCAM (Cell Signaling) and rabbit anti-CD45 (Santa Cruz). EpCAM signals were amplified with Tyramide Signal Amplification System (Life Technologies) according to the manufacturer's protocol. Secondary antibody for CD45 was goat anti-rabbit Alexa 594 (Invitrogen). Nuclei were stained with DAPI and the slides were mounted with Fluoroshield (ImmunoBioscience). Stained cells were observed and photographed on Nikon fluorescent microscope (Eclipse Ti) with X400 objective.

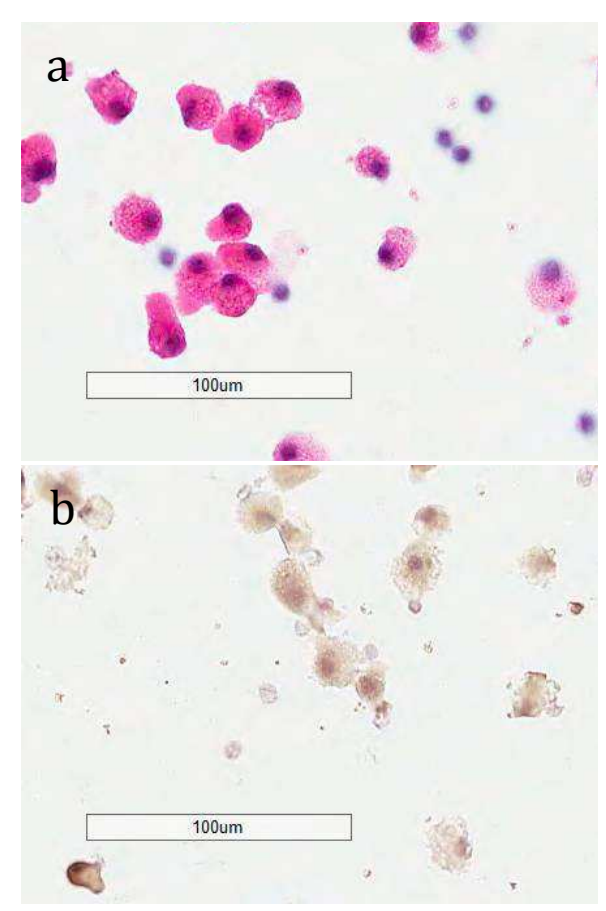

Figure 3. H\&E staining (a) and immunocytochemical staining for EpCAM (b) of cultured CTCs

\subsection{Immunocytochemistry}

Cells were fixed with $4 \%$ formaldehyde for 5 minutes at room temperature, and incubated with $0.3 \%$ peroxide for 20 minutes to block endogenous peroxidase activity. Cells were then permeabilized with $0.2 \%$ Triton X-100 in PBS for 10 minutes, and blocked for 1 hour with 5\% normal goat serum in PBS. Samples were incubated with primary antibody against EpCAM (Cell Signaling) for 1 hour at room temperature, and then with HRP anti-mouse antibody (EnVsion+ DAKO) for 30 minutes. Peroxidase reaction was performed with 3, 3'-diaminobenzidine (DAB) (EnVsion+ DAKO) for 10 minutes. Cells were counterstained with Mayer's Hematoxylin for 10 seconds.

\subsection{Quantitative real-time PCR for EML4-ALK Fusion Detection}

Total RNAs were isolated using QiagenRNeasy Mini kit according to the manufacturer's protocol. cDNAs were generated using oligo(dT) primers and SuperScript III (Invitrogen). Quantitative PCR was performed in $20 \mu \mathrm{l}$ reaction on ABI PRISM 7500 FAST Real-time PCR System
(Applied Biosystems) using AmoyDx EML4-ALK Fusion Gene Diagnostic Kit (AmoyDiagnostics Company Ltd.). $\beta$ Actin was used as an internal control. RNA from MCF-7 cells was included as negative control, and RNAs from $\mathrm{H} 3122$ cells (variant 1) and H2228 (variant 3) as positive controls. $\mathrm{C}(\mathrm{t})$ values below 30 cycles were determined as positive values.

\subsection{FISH for ALK Rearrangement}

FISH was performed on tumor tissue sections using the $A L K$ break-apart probe set (Vysis ALK FISH break-apart kit; Abbott Molecular), following the manufacturer's instructions [10]. Fused signals (adjacent green and red signals) were classified as normal, whereas split signals and single signals were classified as abnormal. For each patient, at least 50 tumor nuclei were scored. ALK FISH-positive cases were defined as more than $15 \%$ of break-apart (BA) signals or an isolated signal in tumor cells.

\section{Results}

\subsection{CTC Cultures}

Being blinded about the presence of ALK arrangement in the patient sample to avoid any bias, we cultured CTCs from 4 lung cancer patients to obtain a sufficient number of CTCs for molecular analysis. Even though minor portion of CTCs was attached to the bottom of culture plates,proliferative CTCs formed spheres from day 4 (Fig. 1),and were allowed to expand for the rest of culture process.

\subsection{CTC Characterization}

After 16-18 days of culture, we characterized the cytological features of CTCs with immunofluorescent (IF) staining for EpCAM asan epithelial cell marker (Fig. 2), and CD45 as a leukocyte marker. About $30 \%$ of the cells were EpCAM positive andCD45 negative and small portion $(\sim 10 \%)$ of cells double positive for EpCAM and CD45. However the majority of double positive cells were large in size, implying that these cells may possibly be CTCs. To confirm this IF finding, aliquots of those cells were immunocytochemically(ICC) stained for EpCAM. Surprisingly, more cells $(40 \sim 50 \%)$ were found EpCAM positive (Fig. 3).

\subsection{Comparison of ALK Rearrangement in Cultured CTCs with that in Tumor Tissues}

To investigate whether cultured CTCs retain molecular characteristics similar to those of primary tumors, cultured CTCs were analyzed for ALK rearrangement by real-time PCR, and compared with FISH result from tumor tissues. Three of 4 lung cancer patients' cultured CTCs (LC-01, 02, 10) were validated for ALK rearrangement as in primary tumor tissue FISH (Fig. 4). The other sample (LC-09), which was originally fusion negative in the primary tumor tissue FISH, did not show positive $\mathrm{Ct}$ value in real-time PCR 
analysis (Fig. 5 and Table 1).

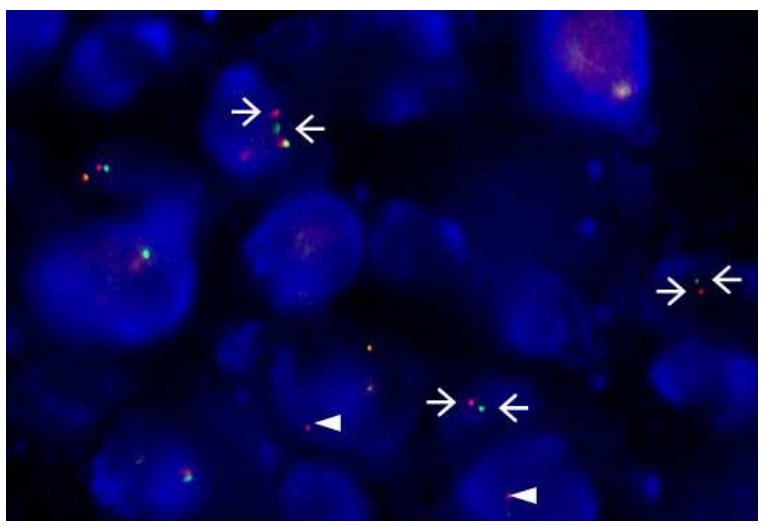

Figure 4. FISH (Fluorescence in situ hybridization) analysis for the detection of $A L K$ rearrangement in lung cancer patient's tissue. Separate red and green signals (arrows) and isolated red signals (arrow heads) were observed.
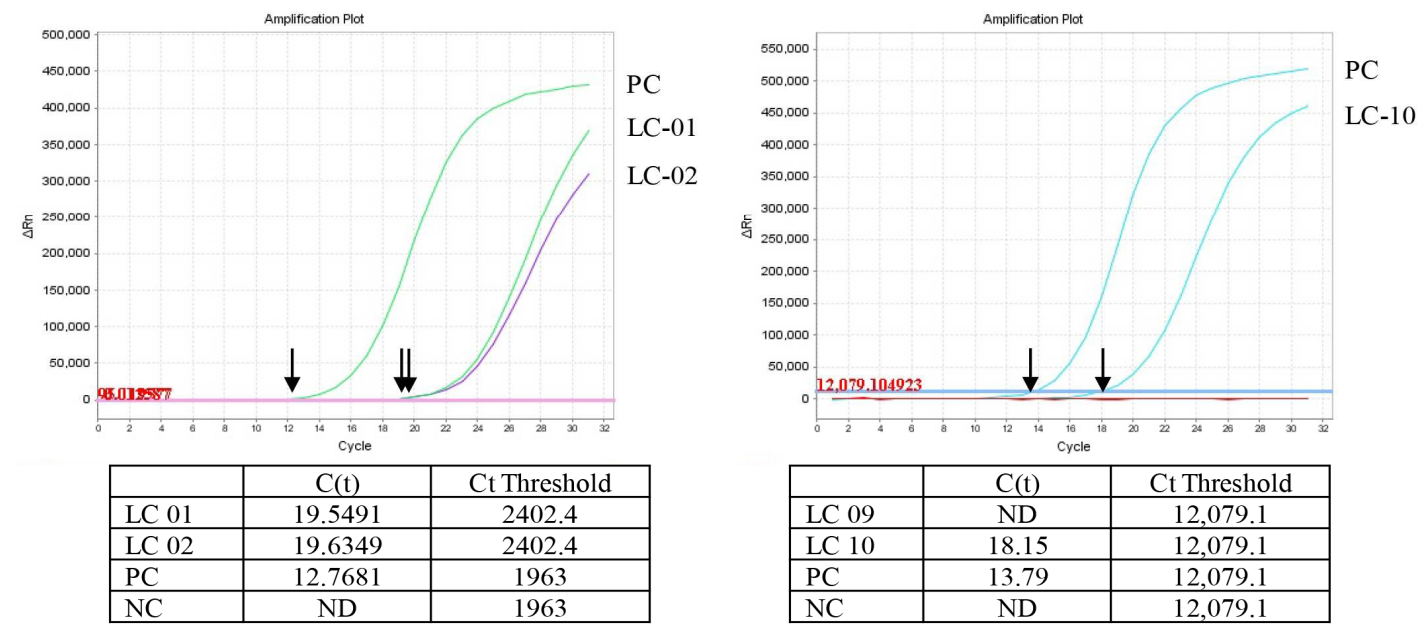

Figure 5. Real-time PCR analysis of cultured CTCs showing positive result (LC01, LC02, LC10) for EML4-ALK transcript.

Table 1. Comparative analysis of ALK rearrangement between NSCLC patients'primary tumors and cultured CTCs.

\begin{tabular}{lll}
\hline Sample & TissueFISH for ALK rearrangement & Cultured CTCqPCR for EML4-ALK \\
\hline LC-01 & + & + \\
LC-02 & + & + \\
LC-09 & - & - \\
LC-10 & + & + \\
\hline
\end{tabular}

\section{Discussion}

We have shown the successful culture of CTCs from lung cancer patients, which can be used for the genomic analysis of tumor cells undergoing metastasis, and the subsequent personalized cancer therapy based upon the genomic information. We observed that the majority of CTCs formednon-adherent spheres, with minor portion as adherent CTCs during the culture process. This observation wasconsistent with the $\mathrm{Yu}$ et al.'s report of CTC cultures from breast cancer patients [11]. However, Zhang et al. reported the adherent CTC cultures from breast cancer patients, different from our observations [12]. We observed that about $30 \%$ of cultured CTC were EpCAM positive and CD45 negative, indicating that still large portion of cultured cells may not be CTCs. But, recent reports demonstrated that disseminated CTCs from the primary tumor frequently undergo the epithelial-to-mesenchymal transition (EMT) during the process of intravasation[13, 14].Others reported that the majority $(>80 \%)$ of CTCs in patients with metastatic tumors co-expressed epithelial markers such as EpCAM, cytokeratins, and E-cadherin, as well as mesenchymal markers including vimentin, $\mathrm{N}$-cadherin and $\mathrm{O}$ cadherin[15].Therefore, double positive (EpCAM+CD45+) or double negative (EpCAM-CD45-) cells in our study cannot be excluded simply as non-CTCs.

ALK rearrangement defines a unique molecular subset in about $7 \%$ of NSCLC patients [16]. ALK rearrangement involves the anaplastic lymphoma kinase $(A L K)$ gene and, most often, the echinoderm microtubule-associated proteinlike $4(E M L 4)[17,18]$. Several different variants of EML4$A L K$ have been described to have different EML4 breakpoints. However, all fusion variants result in gain of function, which 
constitutively activates fusion proteins with potent transforming activity.

Detection of ALK fusion in NSCLC is now performed in routine clinical practice. The diagnosis of $A L K$ rearrangement can be performed by FISH, which is considered as the gold standard, immunohistochemistry (IHC), or reverse transcriptase-polymerase chain reaction (RT-PCR) on these tumor samples. Wang et al. [19] recently reported that FISH was concordant in $98 \%$ of cases with IHC results, and concordant with RT-PCR results in $89 \%$.

In our study, we showed that real-time PCR results in four independently cultured CTCs were compatible with the FISH results in their corresponding primary tumor tissue FISH. From this study, we conclude that we successfullycultured CTCs, which were confirmed to retain the same ALK rearrangement as found in the primary tumor tissue. We also demonstrated that real-time PCR can be successfully employed in the cultured CTCs instead of cell block FISH.

Tumor tissue biopsies may not be an option when serial biopsies are needed for profiling genetic aberrations associated with the development of drug resistance[8]. On the other hand, cultured CTCs from a cancer patients' bloodcan provide us a sufficient number of cells noninvasively, and serial samplings can be madeat different timepoints during treatment to guide therapeutic decisions in a patient's treatment course.For successful application of this strategy to clinical practice, CTC culture conditions should be further optimized. In addition, further confirmative characterization methods, such as different cell marker staining and molecular profiling is desirable for precise identification of cultured CTCs.

\section{References}

[1] Cristofanilli M, Budd GT, Ellis MJ, Stopeck A, Matera J, Miller MC, Reuben JM, Doyle GV, Allard WJ, Terstappen LW, and Hayes DF. Circulating tumor cells, disease progression, and survival in metastatic breast cancer. N Engl J Med (2004) 351:781-91.

[2] Cohen SJ, Punt CJ, Iannotti N, Saidman BH, Sabbath KD, Gabrail NY, Picus J, Morse M, Mitchell E, Miller MC, Doyle GV, Tissing H, Terstappen LW, and Meropol NJ. Relationship of circulating tumor cells to tumor response, progression-free survival, and overall survival in patients with metastatic colorectal cancer. J Clin Oncol (2008) 26:3213-21.

[3] Cristofanilli M, Hayes DF, Budd GT, Ellis MJ, Stopeck A, Reuben JM, Doyle GV, Matera J, Allard WJ, Miller MC, Fritsche HA, Hortobagyi GN, and Terstappen LW. Circulating tumor cells: A novel prognostic factor for newly diagnosed metastatic breaset cancer. J Clin Oncol (2005) 23:1420-30.

[4] de Bono JS, Scher HI, Montgomery RB, Packer C, Miller MC, Tissing H, Doyle GV, Terstappen LW, Pienta KJ, and Raghavan D. Circulating tumor cells predict survival benefit from treatment in metastatic castration-resistant prostate cancer. Clin Cancer Res (2008) 14:6302-9.

[5] Haber DA, Gray NS, and Baselga J. The evolving waron cancer. Cell (2011) 145:19-24.
[6] Yu M, Stott S, Toner M, Maheswaran S, and Haber DA. Circulating tumor cells: approaches to isolation and characterization. J Cell Biol (2011) 192:373-82.

[7] Zer A and Leighl N. Promising targets and current clinical trials in metastatic non-squamous NSCLC. Front Oncol (2014) doi: $10.3389 /$ fonc. 2014.00329 .

[8] Faugeroux V, Pailler E, Auger N, Taylor M, and Farace F. Clinical utility of circulating tumor cells in ALK-positive nonsmall-cell lung cancer. Front Oncol (2014) doi: 10.3389/fonc.2014.00281.

[9] Kim EH, Lee JK, Kim BC, Rhim SH, Kim JW, Kim KH, Jung SM, Park PS, Park HC, Lee J, and Jeon BH.Enrichment of cancer cells from wholeblood using a microfabricated porous filter.Anal Biochem (2013) 440:114-6.

[10] Conde E, Angulo B, Izquierdo E, Muñoz L, Suárez-Gauthier A, Plaza C, Dominguez N, Torres M, Madrigal L, RubioViqueira B, Belda-Iniesta C, Hidalgo M, López-Ríos F.The ALK translocation in advanced non-small-cell lung carcinomas: preapproval testing experience at a single cancer centre.Histopathology (2013) 62:609-16.

[11] Yu M, Bardia A, Aceto N, Bersani F, Madden MW, Donaldson MC, Desai R, Zhu H, Comaills V, Zheng Z, Wittner BS, Stojanov P, Brachtel E, Sgroi D, Kapur R, Shioda T, Ting DT, Ramaswamy S, Getz G, Iafrate AJ, Benes C, Toner M, Maheswaran S, and Haber DA. Ex vivo culture of circulating breast tumor cells for individualized testing of drug susceptibility. Science (2014) 345:216-20.

[12] Zhang L, Ridgway LD, Wetzel MD, Ngo J, Yin W, Kumar D, Goodman JC, Groves MD, and Marchetti D. The identification and characterization of breast cancer CTCs competent for brain metastasis.SciTransl Med (2013) 5:180ra48.

[13] Tsuji T, Ibaragi S, Hu GF. Epithelial-mesenchymal transition and cell cooperativity in metastasis.Cancer Res (2009) 69:7135.

[14] Armstrong AJ, Marengo MS, Otean S, Kemeny G, Bitting RL, Turnbull J, Herold CI, Marcom PK, Geroge D, and GarciaBlanco MA. Circulating tumor cells from patients with advanced prostate and breast cancer display both epithelial and mesenchymal markers. Mol Cancer Res (2011) 9:997-1007.

[15] He H, Yang X, Davidson AJ, Wu D, Marshall FF, Chung LW, Zhau HE, and Wang R.Progressive epithelial to mesenchymal transitions in ARCaPE prostate cancer cells during xenograft tumor formation and metastasis.Prostate (2010) 70:518-28.

[16] Kwak EL, Bang YJ, Camidge DR, Shaw AT, Solomon B, Maki RG, Ou SH, Dezube BJ, Jänne PA, Costa DB, VarellaGarcia M, Kim WH, Lynch TJ, Fidias P, Stubbs H, Engelman JA, Sequist LV, Tan W, Gandhi L, Mino-Kenudson M, Wei GC, Shreeve SM, Ratain MJ, Settleman J, Christensen JG, Haber DA, Wilner K, Salgia R, Shapiro GI, Clark JW, and Iafrate AJ. Anaplastic lymphoma kinase inhibition in nonsmall-cell lung cancer.N Engl J Med (2010) 363:1693-703.

[17] Soda M, Choi YL, Enomoto M, Takada S, Yamashita Y, Ishikawa S, Fujiwara S, Watanabe H, Kurashina K, Hatanaka $\mathrm{H}$, Bando $\mathrm{M}$, Ohno S, Ishikawa $\mathrm{Y}$, Aburatani H, Niki T, Sohara Y, Sugiyama Y, and Mano H. Identification of the transforming EML4-ALK fusion gene in non-small-cell lung cancer. Nature (2007) 448:561-6.

[18] Horn L and Pao W. EML4-ALK: honing in on a new target in non-small-cell lung cancer. J ClinOncol (2009) 27:4232-5. 
[19] Wang J, Cai Y, Dong Y, Nong J, Zhou L, Liu G, Su D, Li X, Wu S, Chen X, Qin N, Zeng X, Zhang H, Zhang Z, and Zhang S. Clinical characteristics and outcomes of patients with primary lung adenocarcinoma harboring ALK rearrangements detected by FISH, IHC, and RT-PCR. PLoS One(2014) 9(7):e101551. 